\title{
CONDIÇÕES DE VIDA: UMA DAS BASES DAS PROPOSTAS DO I CONGRESSO DA INDÚSTRIA E SUA IMPORTÂNCIA PARA O PROJETO DA BURGUESIA INDUSTRIAL BRASILEIRA
}

\author{
CONDITIONS OF LIFE: ONE OF THE BASES OF THE PROPOSALS OF THE FIRST \\ INDUSTRIAL CONGRESS AND ITS IMPORTANCE FOR THE PROJECT OF THE \\ BRAZILIAN INDUSTRIAL BURGOSY
}

Moacir de Freitas Junior ${ }^{1}$

${ }^{1}$ Professor adjunto do Instituto de Ciências Sociais da Universidade Federal de Uberlândia, e-mail: mfir@ufu.br.

\author{
ARTICLE INFO \\ Article history: \\ Received 2019-07-05 \\ Accepted 2019-09-06 \\ Available online 2019-09-06
}

Palavras-Chave: Industrialização. Burguesia. Proletariado. Condições de Vida.

Keywords: Industrialization. Bourgeoisie. Proletariat. Life conditions.

RESUMO. O objetivo deste trabalho é destacar a importância do tema das condições de vida para o projeto político dos industriais brasileiros de se tornarem a força hegemônica de seu tempo, tomando por base as propostas aprovadas para a economia no I Congresso Brasileiro da Indústria, de 1944. Os industriais disputaram politicamente sua ascensão e hegemonia com base em um conjunto de ideias que dotou este segmento de certa unidade política e ideológica que foram fundamentais para os resultados políticos alcançados. Tal disposição permitiu neutralizar em partes o poder do setor agrário e dos setores da burguesia não associados à ideia de um plano de desenvolvimento, bem como abriram espaço para a aproximação do proletariado, que passou a defender o projeto industrialista de desenvolvimento, vislumbrando em tal aliança um maior espaço político para defender os interesses dos trabalhadores, que naquele momento histórico lutavam por melhores condições de vida e de trabalho e também para se consolidar enquanto classe social com interesses políticos próprios. Ressalta-se o papel de Roberto Simonsen para este processo, responsável por formular e apresentar as propostas debatidas no trabalho, defendia que a pauperização precisaria ser superada, a fim de que o Brasil pudesse se estabilizar socialmente; ainda, que a pobreza só seria superada pela industrialização.

ABSTRACT. The purpose of this paper is to highlight the importance of the theme of living conditions for the Brazilian industrialists' political project to become the hegemonic force of their time, based on the proposals approved for the economy in the First Brazilian Congress of Industry, 1944. The industrialists disputed politically their ascent and hegemony based on a set of ideas that endowed this segment with a certain political and ideological unity that were fundamental for the obtained political results. This arrangement made it possible to neutralize in part the power of the agrarian sector and of the sectors of the bourgeoisie not associated with the idea of a development plan, as well as opening space for the proletariat to approach the industrialist project of development, foreseeing in such an alliance a greater 
political space to defend the interests of the workers, who in that historical moment fought for better conditions of life and work and also to consolidate itself as a social class with its own political interests. Roberto Simonsen's role in this process, responsible for formulating and presenting the proposals discussed in the paper, was emphasized; he argued that pauperization would have to be overcome, so that Brazil could stabilize itself socially; still, that poverty would only be overcome by industrialization.

\section{Introdução}

O objetivo deste trabalho é destacar a importância do tema das condições de vida para o projeto político dos industriais brasileiros de se tornarem a força hegemônica de seu tempo, tomando por base as propostas aprovadas para a economia no I Congresso Brasileiro da Indústria, de 1944.

Os industriais disputaram politicamente sua ascensão e hegemonia com base em um conjunto de ideias que dotou este segmento de certa unidade política e ideológica que foram fundamentais para os resultados políticos alcançados. Este conjunto de proposta tinha o propósito de consolidar a classe industrial como força hegemônica, tanto na economia quanto no Estado, com a ocupação dos postos técnicos e políticos de formulação e decisão acerca das políticas econômicas e foram sintetizadas nas propostas apresentadas e debatidas durante o I Congresso Brasileiro da Indústria, que aprovou 137 teses sobre temas os mais variados acerca do desenvolvimento da indústria brasileira.

O I Congresso Brasileiro da Indústria aconteceu de 08 a 14 de dezembro de 1944. Em nosso entendimento, o objetivo do Congresso era fixar uma base de propostas da classe industrial brasileira, seus anseios e intenções para a economia brasileira e o papel do Estado em relação a este ramo econômico. Este conjunto de proposta, entendemos, tinha o propósito de consolidar a classe industrial como força hegemônica, tanto na economia quanto no Estado, com a ocupação dos postos técnicos e políticos de formulação e decisão acerca das políticas econômicas.

Na busca destes objetivos, que a indústria já vinha perseguindo há mais de uma década, a classe industrial brasileira mobilizou-se. Foram apresentadas 137 teses, versando sobre temas os mais variados acerca do desenvolvimento da indústria brasileira, desde o modo de organização da produção até a planificação da economia, passando pelas relações de classe com o operariado e sua qualificação, a legislação trabalhista e social, entre outros temas. Participaram do Congresso 324 congressistas, representando 191 entidades, que variam entre sindicatos, órgãos estatais, indústria propriamente ditas e outros, de todo o Brasil.

Ao todo, sete comissões técnicas foram montadas para diagramar as propostas apresentadas e aprovada, sendo a primeira Comissão a de sistematização e as demais debatendo planificação econômica; reajustamento da produção industrial para o período pós- 
guerra; fatores de encarecimento da produção industrial; normas para harmonização entre as classes; fibras nacionais.

Para compor a Segunda Comissão, responsável pela formulação das propostas de caráter político-econômico, foram escalados Roberto Simonsen e Cyro Berlink, além de Álvaro de Souza Lima, João Luderitz e outros 27 membros. Foi nesta Comissão que Simonsen, que também presidiu a Comissão Técnica e de Redação e foi o Vice-Presidente do Congresso (presidido por Evaldo Lodi), apresentou as teses sobre as quais debateremos a seguir, que foram aprovadas.

A importância do I Congresso, ao nosso ver, reside na possibilidade de ele significar a maturidade de um processo que se iniciou décadas antes e que se consolidou anos depois de seu acontecimento, que é a hegemonia econômica, política e de ideias da burguesia industrial sobre os caminhos econômicos do Brasil. Neste sentido, as bases de tal hipótese assentam-se na perspectiva de que a burguesia nacional tinha ideias claras sobre os destinos que pretendia para o Brasil; um plano pensado e de aceitação coletiva sobre como atuar.

Octávio lanni (2004) explica que as discussões sobre a vocação econômica brasileira desenvolveram-se desde os anos 1920, sendo que o projeto de industrialização ganhou maior impulso a partir dos acontecimentos da década de 1930, oportunidade em que as teses industrialistas lograram a ascensão ao poder e, a partir de tal movimento, iniciaram a jornada rumo à construção de um capitalismo nacional (IANNI, 2004, p.52).

O autor destaca que o projeto de capitalismo nacional foi bem-sucedido, na medida em que, não obstante todas as suas limitações, possibilitou a criação de ampla e complexa economia nacional baseada na industrialização; transformou as condições e perspectivas da sociedade e da política, iniciando a formação da categoria social "povo", bem como outras transformações de cunho cultural (IANNI, 2004, p.61).

Diniz e Boschi (1978) também apontam que o papel dos empresários industriais para a consolidação da política industrial a partir dos anos 1930 foi fundamental. Não obstante exista importante corrente intelectual com entendimento diverso, que defende ter sido o processo mais um arranjo conservador do que de mudanças propriamente ditas, cuja melhor expressão está no conceito de "modernização conservadora" de Barrington Moore Jr. (1975), também debatido por Fausto (1970), Velho (1976) e outros, Diniz e Boschi (1978) entendem que a Revolução de 1930 não pode ser tomada somente por seu aspecto conservador, na medida em que o projeto industrial acabou por prevalecer.

Discordando em parte das análises de que o governo de então não tinha um projeto industrial e sequer um consenso sobre quais diretrizes econômicas seguir, ora adotando 
políticas ortodoxas, ora acenando com medidas favoráveis ao industrialismo (FAUSTO, 1970), os autores apontam que foi exatamente esta falta de diretrizes pré-estabelecidas que permitiu à burguesia industrial atuar em favor de seu projeto, o que de fato aconteceu, em detrimento das ideias anti-industriais. (DINIZ e BOSCHI, 1978, p.50-51). Assim, longe de ser um grupo social fragilizado e desarticulado, a burguesia industrial - ou ao menos expressivos setores dela - tinha um projeto e disputou sua implantação junto ao Estado, sendo que os sucessos obtidos com a orientação da política econômica pró-industrialização seriam fruto direto de tal atuação.

As propostas de cunho econômico mais específico e que nos interessam mais no presente trabalho foram debatidas na Segunda Comissão, intitulada "Planificação econômica do Brasil no setor das atividades industriais". A comissão apresentou e fez aprovar um relatório de 14 seções e 117 propostas, que por conta do espaço não poderemos analisar aqui em sua totalidade. Por conta disso, nosso recorte se concentrará nas medidas mais imediatamente ligadas à questão das condições de vida, do projeto político industrialista e de sua defesa da intervenção estatal no setor, inclusive com o planejamento econômico nesta área, dando mostras dos caminhos escolhidos por este setor da burguesia nacional para alcançar a hegemonia política e econômica.

\section{O papel de Roberto Simonsen para a consolidação deste processo}

Mas, como a consolidação destas ideias deu-se ao longo das décadas anteriores, possibilitando sua condensação no plano apresentado no I Congresso? Neste quesito, a importância da atuação de Roberto Simonsen merece destaque, não obstante não seja propriamente o centro deste trabalho.

Simonsen foi um empresário e intelectual que se tornou um dos maiores líderes da burguesia industrial do Brasil da primeira metade do século XX. Foi, em grande parte, graças a suas ações que os industriais atuaram buscando influenciar a política econômica da época. Sua ascensão como pensador e líder de sua classe se deu ao mesmo tempo em que no Brasil ocorria, especialmente a partir da década de 1930, a implantação do capitalismo industrial, o fortalecimento do Estado como fator decisivo para a industrialização e, consequentemente, a chegada da burguesia nacional ao poder, para os quais contribuiu diretamente.

Melhor situando a condição e a importância intelectual da obra de Simonsen e sua conexão com a questão da superação do subdesenvolvimento, Vera Cepeda (2004 e 2007) aponta que o problema fundamental com o qual a obra de Simonsen debateu-se era 0 subdesenvolvimento do Brasil, suas causas e as maneiras pelas quais ele poderia ser 
superado. Sobre esta questão, ver ainda Vieira (2010), Corsi e Mendonça (2010), Colistete (2007), Carone (1971 e 1977), Bielschowsky (2000), Lima (1976), Leme (1978) Del Vecchio e Diéguez (2008), Freitas (2011, 2013a e 2013b), Maza (2004), Rompatto (2004), LEAO, PINTO e SILVA (2015), entre outros.

O tema das condições de vida e de sua superação pelo desenvolvimento econômico industrial aparece em todas as fases do pensamento de Simonsen ao longo de sua carreira intelectual e prática. E é exatamente a construção destas teses, ao mesmo tempo em que liderou a classe industrial brasileira neste período, que ao nosso ver permitiu que a classe industrial brasileira se firmasse enquanto tal, podendo disputar a hegemonia econômica e política que almejava tendo como base ideológica um arcabouço de ideias sobre como o Brasil deveria conduzir, através do Estado, sua industrialização. Tais ideias transcenderam a Roberto Simonsen e se tornaram o próprio projeto industrialista da época, o que confere ao autor e sua obra importância fundamental.

Esta consolidação de ideias e, mais precisamente, a simbiose delas com Getúlio Vargas e o Estado, deu-se no I Congresso Brasileiro da Indústria, presidido pelo próprio Presidente da República e palco final da união política que deu à indústria o status de força política e econômica do Brasil daquele período. Daí a importância do estudo destes materiais e, principalmente, das ideias neles contidas, que nos ajudam a compreender melhor a grandeza desta chave histórica do pensamento brasileiro.

\section{As propostas dos industriais para a economia e o tema das condições de vida}

Nos dias 15, 16 e 17 de dezembro de 1944, a comissão de redação reuniu-se em caráter permanente para discutir as propostas apresentadas pela Segunda Comissão. Os debates entre os membros não foram transcritos integralmente nas atas, mas nelas ficou registrado uma questão importante para os fins deste trabalho, que foi a incorporação, feita pelo próprio Simonsen, dos itens aprovados na Conferência Internacional de Rye, acontecida em Nova York em 1944, meses antes do I Congresso da Indústria, especialmente a parte que fala da questão do "contra o intervencionismo do Estado".

A Conferência de Rye aconteceu meses antes do fim da Segunda Guerra Mundial e já tinha por propósito preparar novas bases para a economia nacional. Novas, no caso, é força de expressão, pois a proposta que os EUA estavam formulando para os países da América Latina era a retomada dos termos de trocas comerciais estabelecidos antes da II Guerra, nos quais os países em desenvolvimento não deveriam buscar a industrialização, mas sim seguir 
com sua "vocação natural" agrário-exportador, o que na prática sufocaria os ainda incipientes parques industriais locais, contrariando por completo os interesses da burguesia industrialista nacional.

A delegação brasileira para a Conferência de Rye, presidida por João Dault de Oliveira apresentou importantes propostas que perpassaram por temas como a construção de uma política de desenvolvimento dos países mais pobres, da função social do capital, entre outras. Uma, em especial, merece nossa atenção: a de que os países em desenvolvimento não deveriam abandonar o suporte do Estado - o protecionismo - como parte da estratégia de desenvolvimento econômico.

Apesar do cuidado próprio de tratamento das questões políticas, a ideia constante do debate era clara e associada ao que pensava parte da burguesia brasileira: não era do interesse dos industriais abrir mão do apoio das políticas estatais para sua consolidação, pois sem elas não haveria como o setor se estabelecer de modo hegemônico.

É este o espírito que, em nosso ver, encontramos nas propostas econômicas de planejamento da economia e intervenção estatal: o Estado deve proteger e promover a industrialização (no caso, do Brasil) porque este seria o caminho do desenvolvimento. Não se trataria, portanto, de "intervenção" estatal na economia, mas de proteção. O eufemismo, entendemos, serve para não alimentar a polêmica com os demais setores da economia e mesmo dentro da burguesia industrial acerca dos pilares da economia liberal, mas claramente aponta para o que defendia o setor industrialista e parte importante dos demais setores econômicos: sem o Estado, não haveria como consolidar o capitalismo brasileiro em bases fortes o suficiente para nos elevar à categoria de país desenvolvido.

A redação das propostas dá bem o tom do que os industriais brasileiros procuravam defender. O item I da proposta denomina-se "planificação estatal; o que deve abranger" e defende a planificação da economia pelo Estado com o intuito de promover o desenvolvimento da indústria, ainda que apareça, nas propostas, como um plano de desenvolvimento do Brasil como um todo, reforçando o caráter ideológico que estas propostas tinham para os industriais brasileiros e seus interesses.

I - Planificação industrial; o que deve abranger CONSIDERANDO:

a) que é baixo o nível de vida do brasileiro e pouco elevada a nossa renda nacional;

b) que nosso aparelho econômico e, sobretudo, o nosso equipamento industrial é precário e, em grande parte, antiquado;

c) que a planificação representa uma técnica econômica de melhoria da produção;

d) que, no povo brasileiro, já está solidificado o conceito clássico de democracia como um desejo de assegurar a plenitude da liberdade; 
e) que é possível planificar a economia de um país, garantindo a primazia da iniciativa particular;

f) que, no caso brasileiro, a planificação, além do mais, significa a recuperação do tempo perdido;

g) que é um dos objetivos da planificação assegurar a maior e mais eficiente utilização da mão-de-obra e dos recursos naturais;

h) que a planificação econômica nacional deve abranger o trato dos problemas industriais, agrícolas e comerciais, bem como o dos sociais e econômicos, de ordem geral;

i) que a observação do processo econômico internacional, no período anterior à guerra, demonstrou, dentro do ritmo normal da evolução, social e econômica, não ser possível, à maioria das nações empobrecidas por falta de recursos naturais, baixa produtividade das populações, ambiente geográfico e outras causas, alcançar, rapidamente, um nível de renda nacional que lhes permita assegurar um padrão de vida conveniente,

O CONGRESSO BRASILEIRO DA INDÚSTRIA RECONHECE

(...)

5) Que a renda nacional, representada em bens produzidos e avaliados, atualmente, em cerca de 40 bilhões de cruzeiros, necessita ser pelo menos quadruplicada dentro do menor prazo possível, para que a população brasileira possa usufruir um razoável padrão médio de vida.

RECOMENDA

8) Que se proceda a uma planificação econômica, que tenha por fim, dentro de um determinado período, aumentar a produtividade e criar as riquezas necessárias para alcançarmos uma suficiente renda nacional.

(ANAIS DO I CONGRESSO DA INDÚSTRIA, 1944, p. 183-184)

Procuramos, nesta longa citação da proposta, separar os trechos em que os industriais brasileiros procuram apresentar o conjunto de ideias que são de seu total interesse como se fossem ideias de um futuro próspero para todo o Brasil, ressaltando o caráter ideológico destas ideias na luta por sua hegemonia. Assim, temos nos "considerando", logo no item "a", que é "baixo o nível de vida" e "pouco elevada" a renda nacional, ou seja: o Brasil era um país pobre.

Uma leitura possível e que já fizemos em trabalhos anteriores é que os industriais brasileiros utilizavam a pobreza para esgrimir questões políticas, entre as quais a disputa com o setor agrário exportador. Ora, se até então as bases econômicas do Brasil se assentavam na economia de produção de matérias-primas e sua exportação e posterior troca por manufaturados importados; e se o Brasil era um país pobre com uma população também pobre em relação aos demais países, a conclusão era a de que o sistema econômico agrário exportador era um gerador de pobrezas.

E, se era assim, nada mais correto do que alterar as bases produtoras nacionais para a industrialização, um modelo capaz de gerar riqueza, aumentar a produção e, com isso, 
aumentar o padrão de vida da população como um todo: a indústria. A discussão aparece novamente na proposta número 4, acima transcrita: a evolução econômica é "absolutamente insuficiente para as necessidades" de crescimento da população. Logo, o que se deve fazer, como vimos na proposta 8 também transcrita: "planificar a economia" para "aumentar a produção" e "criar as riquezas necessárias para (...) uma suficiente renda nacional", mas não através da agricultura e sim da indústria.

Vendo por este ângulo, as demais propostas de planificação ganham uma nova conotação: o plano é organizar a economia - e a política - para a industrialização, em detrimento (ainda que não em oposição direta) dos demais setores da economia, especialmente o agrário, que aparece como "antiquado" e "ineficiente", ao passo em que a indústria, neste contexto, passa a significar "democracia", "eficiência", o modo de produção capaz de "elevar os padrões de vida" da população brasileira.

Ainda neste diapasão, notemos que o considerando "i" da proposta I dialoga com outras questões de igual tamanho político e teórico, ao afirmar que, estudando a história do desenvolvimento econômico até antes da II Guerra, não se pode afirmar que o desenvolvimento é uma questão "de tempo" e que este havia chegado primeiro aos países centrais, mas ao contrário: a evolução social e econômica pretendida - ou seja, sair da pobreza e alcançar um outro patamar material superior - nunca aconteceria sem que houvesse, por parte do Estado e, aqui sim, da Nação, um plano de desenvolvimento que direcionasse os recursos e energias disponíveis nesta direção.

Uma vez mais podemos ver os industriais dialogando, agora por meio das propostas aprovadas no I Congresso Brasileiro da Indústria, de modo crítico com os demais setores da economia nacional que não aceitavam o protagonismo industrial e defendiam a "vocação agrária" do Brasil, bem como com os que repudiavam o planejamento econômico e a intervenção estatal, contradições estas que apareciam tanto internamente, por meio da parcela dos industriais mais alinhados a políticas liberais e individuais, bem como externamente entre os setores, especialmente o agrário, que ansiavam não perder o protagonismo econômico e político de que gozaram até então.

Ainda, fica claro que os industriais brasileiros dos anos 1940 tinham uma profunda consciência da situação econômica nacional e mundial, além de um vasto conhecimento das teorias econômicas até então existentes, a ponto de antecipar questões de teoria econômica que só apareceriam como resolvidas anos depois (como os termos de troca, o abandono da "vocação natural" e outros").

Considerando os argumentos acima expostos, entendemos ser possível afirmar que os industriais brasileiros, na luta por se tornar a força hegemônica na política e na economia brasileiras de então, desenvolveram um arsenal de propostas ideológicas que serviam tanto 
para mobilizar o próprio segmento como para balizar sua atuação em relação aos demais setores da economia.

Esta hipótese se reforça quando analisamos a II proposta, "Intervencionismo do Estado e iniciativa particular". Nela, pesavam dois fatores importantes: por um lado, a indústria brasileira não se desenvolveria sem o apoio e o aporte de recursos do Estado, especialmente nas indústrias de base, sem as quais o setor não se consolidaria. Por outro lado, não era politicamente viável que os industriais exigissem abertamente do Estado que este bancasse a industrialização nacional, ainda que esta fosse a ideia, dadas as contradições ideológicas e políticas sobre as quais tratamos acima. Havia, ainda, a questão política de que a planificação econômica era um recurso das economias socialistas, o que também poderia ser utilizado como arma ideológica contra a burguesia industrial.

Por tudo isso, a proposta procurou diferenciar intervenção estatal de "intervencionismo", adquirindo as feições de um "plano nacional" de desenvolvimento e não da gestão estatal da economia. Vejamos:

\section{II - Intervencionismo do Estado e iniciativa particular} CONSIDERANDO:

a) que a planificação industrial do Brasil deve orientar-se no sentido de se alcançar o máximo do aproveitamento econômico;

b) que os planejamentos industriais, salvo casos excepcionais, devem ser elaborados à margem do autoritarismo do Estado, que neles deve colaborar como órgão incentivador, atendendo o sentido social da produção;

O CONGRESSO BRASILEIRO DA INDÚSTRIA RECONHECE

13) Que o Estado, longe de interferir diretamente pelo comando no campo econômico, deve acentuar a sua influência no sentido de criar condições que assegurem a permanência do desenvolvimento das atividades privadas que são a essência da prosperidade da nação.

\section{CONSIDERANDO}

a) que ao Estado incumbe, além das atividades normais, a tarefa de manter os trabalhos e instituições públicas que ultrapassem o alcance das iniciativas privadas, já por serem muito custosas, já por sua influência social;

b) que incumbe ao Estado, a fim de empreender a necessária organização planificadora da economia, a criação de órgãos técnicos que deverão funcionar com a participação direta das classes produtoras;

\section{RECOMENDA}

14) Que a intervenção do Estado, no campo econômico, seja:

a) supletiva, cabendo-Ihe interferir para assegurar os bens gerais e permanentes da coletividade;

b) planificadora, no sentido de articular racionalmente as forças produtoras e conseguir, assim, o levantamento geral do nível de vida;

c) auxiliadora, para a concessão de facilidades que incentivem a produção.

15) Que o Estado: 
a) estimule a iniciativa particular, a fim de obter a almejada expansão e desenvolvimento econômico nacional;

b) estimule a cooperação de todas as atividades no sentido de se organizar uma sólida estrutura social e econômica.

(ANAIS DO I CONGRESSO BRASILEIRO DA INDÚSTRIA, 1944, p. 184-185)

A redação da proposta, como vimos, procurou apresentar com cuidado esta "intervenção não intervencionista" dando a ela a feição de um plano: ao Estado caberia planejar a demanda, mobilizar os recursos, facilitar sua alocação no desenvolvimento industrial, em suma, deveria ser o artífice da indústria nacional, mas sem nela intervir diretamente. Daí a ideia de um planejamento nacional, com o objetivo de alcançar o desenvolvimento com base na industrialização.

Quando analisamos as duas propostas em conjunto, o sentido político das colocações ganha mais força: sendo a pobreza e as condições de vida um entrave para o desenvolvimento econômico do país e não sendo o setor agrário-exportador capaz de elevar este patamar; bem como sendo certo que o desenvolvimento econômico não seria conquistado com o tempo, mas deveria ser construído de maneira planejada, caberia ao Estado promover o setor industrial, alocando seus recursos e poderes para abrir o caminho da industrialização, tudo com base no "interesse nacional", que aqui aparece misturado com as pretensões políticas da burguesia industrial da época, em uma interseção de interesses muito bem construída.

Mas esta intervenção estatal não poderia aparecer como um benefício ao setor industrial, mas sim como um plano nacional capaz de elevar a produção, a riqueza, o desenvolvimento e, com isso, mudar o país de patamar econômico, melhorando as condições de vida dos trabalhadores, dos produtores rurais, dos comerciantes, enfim, de todos os setores econômicos de então.

Nestes termos, portanto, as propostas dos industriais para desenvolver o seu segmento econômico e político são apresentadas como propostas de prosperidade para toda a nação, ampliando as possibilidades de apoio de outros segmentos e classes ao projeto (notadamente, os trabalhadores) e abrindo espaço para os divergentes aceitarem a condição hegemônica do setor, em troca do "desenvolvimento do Brasil".

Em suma, são propostas com funções ideológicas claras: mobilizar o setor industrial em torno de seus interesses; abrir espaço político no Estado para garantir a adoção de medidas e políticas públicas de desenvolvimento que fossem dos interesses dos industriais; angariar apoios políticos dos demais segmentos econômicos e classes sociais; esgrimir com os setores divergentes, isolando-os politicamente. As condições de vida - e sua elevação por 
meio da indústria - aparecem como tema político chave capaz de unificar industriais e trabalhadores em prol do projeto de desenvolvimento industrialista.

\section{Considerações Finais: ideias e ideais dos industriais brasileiros e o projeto nacional desenvolvimentista}

Considerando os argumentos até aqui expostos, entendemos ser possível afirmar que os movimentos políticos dos industriais dos anos 1930 e 1940 foram precursores dos entendimentos posteriores sobre os quais se assentou o projeto nacional-desenvolvimentista a partir dos anos 1950, ao lançar as bases do que seria o apoio estatal ao setor e de como tal segmento deveria se comportar em relação a seu fortalecimento.

Ainda, que estes posicionamentos também refletiram nos demais segmentos econômicos e políticos nacionais de então, seja neutralizando em partes o poder do setor agrário e dos setores da burguesia não associados à ideia de um plano de desenvolvimento (aqui, nos referimos a ocupar os postos de comando do Estado e de formular as políticas econômicas, não do poder político), bem como abriram espaço para a aproximação do proletariado, que passou a defender o projeto industrialista de desenvolvimento, vislumbrando em tal aliança um maior espaço político para defender os interesses dos trabalhadores, que naquele momento histórico lutavam por melhores condições de vida e de trabalho e também para se consolidar enquanto classe social com interesses políticos próprios.

Importa também, por fim, ressaltar o papel de Roberto Simonsen para este processo. No I Congresso, ele foi o responsável por formular e apresentar as propostas que aqui debatemos, em conjunto com os demais membros da comissão. Mas nos antecedentes ao I Congresso, Simonsen deu contribuições fundamentais para a consolidação destas ideias entre os industriais brasileiros, ao afirmar ao longo de suas obras, discursos, artigos e atuações que a pauperização precisaria ser superada, a fim de que o Brasil pudesse se estabilizar socialmente; ainda, que a pobreza só seria superada pela industrialização; e por fim, que a industrialização só seria plenamente implantada com a planificação da economia pelo Estado, construindo os alicerces onde se ergueu o projeto industrialista brasileiro e, arriscamos afirmar, a própria identidade de classe burguesa nacional, que ao instituir como suas tal corolário de ideias acerca do Brasil e de seu próprio papel na construção da economia nacional, se estabeleceu como força política dotada de uma ideologia de classe própria.

É certo que o setor industrial tinha interesses financeiros neste processo. Mas o centro de sua atuação e de seu lucro não estavam na forma como a indústria seria tratada pelo 
governo, mas sim em direcionar as ações do Estado em seu favor, assumindo posição hegemônica ao fazer com que seus objetivos se tornassem os mesmo da "democracia", da "ordem econômica" e outros, em uma escala de profundidade que extrapola, em nosso ver, a possibilidade de os industriais terem agido sem base ideológica e sem que os conceitos já aqui apresentados tenham sido este alicerce.

Estas são hipóteses que buscamos analisar e que, em nosso ver, apontam para a conclusão que o I Congresso Brasileiro da Indústria representa um dos marcos na consolidação da hegemonia econômica e política dos industriais brasileiros do período, movimento que se consolidou anos depois no projeto nacional-desenvolvimentista, selando em definitivo a ascensão da burguesia aos postos de comando do Estado, da economia e da política brasileiras.

\section{REFERÊNCIAS}

ANAIS DO I CONGRESSO BRASILEIRO DA INDÚSTRIA. São Paulo: CNI/FIESP, 1945. ATAS DO I CONGRESSO BRASILEIRO DA INDÚSTRIA. São Paulo, CNI/FIESP, 1945. BIELSCHOWSKY, Ricardo. Pensamento Econômico Brasileiro. O ciclo ideológico do desenvolvimentismo. 4⿳亠丷a edição, Rio de Janeiro: Contraponto, 2000.

CARONE, Edgard. Roberto C. Simonsen e sua Obra. RAE - Revista de Administração de Empresas, Rio de Janeiro: 11(4): p.23-28, out/dez de 1971.

CARONE, Edgard. O pensamento industrial no Brasil. 1880-1945. Rio de Janeiro/São Paulo: Difel, 1977.

CEPEDA, Vera. Roberto Simonsen e a formação da ideologia industrial no Brasil: limites e impasses. 2004. Tese. (Doutorado em Ciência Política) - Faculdade de Filosofia, Letras e Ciências Humanas, Universidade de São Paulo, São Paulo.

CEPEDA, Vera. Estado, Democracia e Nação na teoria do subdesenvolvimento. Trabalho apresentado no XII Encontro Nacional de Economia Política, junho de 2007. Disponível em: <http://www.sep.org.br/artigo/_861_d4b012a6ed845f6bac443e6cd55e34a7.pdf>. U Último acesso em 30 de set. de 2009.

CEPEDA, Vera. O problema do moderno no pensamento de Roberto Simonsen: crítica ao liberalismo e a questão nacional. In: XV Congresso Brasileiro de Sociologia, 2011, Curitiba. Anais do XV Congresso Brasileiro de Sociologia, 2011, sem paginação.

COLISTETE, Renato Perim. A força das idéias: a CEPAL e os industriais paulistas na primeira metade da década de 1950. in História Econômica \& História de Empresas, vol. X , 2006, p. 123-153.

CORSI, Francisco Luiz; Camargo, José Marangoni (org). Celso Furtado: os desafios do desenvolvimento. São Paulo: Cultura Acadêmica; Marília: Oficina Universitária, 2010.

DEL VECCHIO, Angelo; DIÉGUEZ, Carla. As pesquisas sobre o padrão de vida dos trabalhadores da cidade de São Paulo. Horace Davis e Samuel Lowrie, pioneiros da sociologia aplicada no Brasil. Editora Sociologia e Política: São Paulo, 2008.

DINIZ, Eli; BOSCHI, Renato Raul. Empresariado Nacional e Estado no Brasil. Rio de Janeiro: Forense-Universitária, 1978.

FAUSTO, Boris. A Revolução de 1930. São Paulo: Brasiliense, 1970.

FREITAS, Moacir Jr. O industrial e o salário: a contribuição de Roberto Simonsen para os estudos sobre o padrão de vida dos trabalhadores no Brasil. 2013. Tese (doutorado em Ciências Sociais) - Faculdade de Ciências e Letras da Universidade Estadual Paulista UNESP, campus de Araraquara. 
FREITAS, Moacir Jr. Um Plano Marshall para a América Latina: a contribuição de Roberto Simonsen para a tese do subdesenvolvimento latino-americano. In XXIX Congresso da Associação Latino-americana de Sociologia - ALAS, Chile, 2013, GT Pensamento Latinoamericano.

FREITAS, Moacir Jr. Desenvolvimento Econômico e condições de vida: a força de uma ideia e uma ideia força na obra de Roberto Simonsen. Publicatio UEPG Appl. Soc. Sci., Ponta

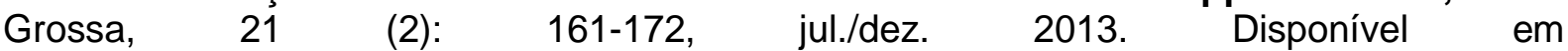
http://www.revistas2.uepg.br/index.php/sociais.

FREITAS, Moacir Jr. I Congresso Brasileiro da Indústria: marco da construção da hegemonia dos industriais brasileiros. XVIII Congresso da SBS, Brasília, abril de 2017a, disponível em http://sbs2017.com.br/anais/resumos/PDF-eposter-trab-aceito-0399-1.pdf, acesso em 10 de janeiro de 2019.

FREITAS JUNIOR, Moacir. I congresso da indústria de 1944: um marco na consolidação da hegemonia da burguesia industrial brasileira. In: ENCONTRO NACIONAL DA ANPOCS, 41., 2017b, Caxambu. Anais... Caxambú, 2017. Disponível em: <www.anpocs.org.br>. Acesso em: 14 fev. 2019.

IANNI, Octávio. Pensamento Social no Brasil. Bauru: Edusc/ANPOCS, 2004

LEAO, Igor Z. C. Carneiro; PINTO, Thiago L. Q. Ramos; SILVA, Newton G. Roberto Simonsen na origem do moderno pensamento social brasileiro. Econ. soc., Campinas, v. 24, n. 1, p. 177-199, Apr. $2015 . \quad$ Available from http://www.scielo.br/scielo.php?script=sci arttext\&pid=S0104-

06182015000100177\&lng=en\&nrm=iso. http://dx.doi.org/10.1590/1982-3533.2015v24n1art7.

LEME, Marisa Saens. A Ideologia dos Industriais Brasileiros (1919-1945). Petrópolis: Vozes, 1978.

LIMA, Heitor Ferreira. Três industrialistas brasileiros: Mauá, Rui Barbosa, Roberto Simonsen. São Paulo: Alfa-Ômega, 1976.

MAZA, Fábio. O idealismo prático de Roberto Simonsen: ciência, tecnologia e indústria na construção da nação. São Paulo: Instituto Roberto Simonsen, 2004.

MOORE JR, Barrington. As Origens Sociais da Ditadura e da Democracia. Lisboa: Edições Cosmos, 1967.

ROMPATO, Maurílio. Roberto Simonsen e a evolução sem revolução. 2004. 384p. Tese (Doutorado em História) - Unesp, Assis, 2004.

VELHO, Otávio Guilherme. Capitalismo Autoritário e Campesinato (Um estudo comparativo a partir da Fronteira em movimento). São Paulo: Difel, 1976.

VIEIRA, Rosangela de Lima. A presença da história no pensamento de Celso Furtado. In: Corsi; Camargo (org). Celso Furtado: os desafios do desenvolvimento. SP: Cultura Acadêmica; Marília: Oficina Universitária, 2010, p. 41-52.

SIMONSEN, Roberto. Orientação industrial brasileira. São Paulo: São Paulo Editora Ltda, 1928.

As crises no Brasil. São Paulo: São Paulo Editora, 1930.

As finanças e a indústria. São Paulo: São Paulo Editora, 1931.

À margem da Profissão - discursos, conferências e publicações. São Paulo: São Paulo Editora, 1932.

. Rumo à verdade. São Paulo: São Paulo Editora, 1933.

Ordem econômica, padrão de vida e algumas realidades brasileiras. São Paulo: São Paulo Editora, 1934.

- A evolução industrial do Brasil. São Paulo: Empresa Gráfica da Revista dos Tribunais, 1939.

. Níveis de vida e a economia nacional. São Paulo, sem editora, 1940. 